\title{
Sulfate transporters in the plant's response to drought and salinity: regulation and possible functions
}

\author{
Karine Gallardo ${ }^{1}$, Pierre-Emmanuel Courty ${ }^{2}$, Christine Le Signor $^{1}$, Daniel Wipf ${ }^{3}$ and Vanessa Vernoud ${ }^{1}$ \\ 1 Institut National de la Recherche Agronomique, UMR1347 Agroécologie, Dijon, France \\ 2 Zurich-Basel Plant Science Center, Department of Environmental Sciences, Botany, University of Basel, Basel, Switzerland \\ ${ }^{3}$ Université de Bourgogne, UMR1347 Agroécologie, Dijon, France
}

\section{Edited by:}

Ruediger Hell, University of

Heidelberg, Germany

\section{Reviewed by:}

Chengbin Xiang, University of Science and Technology of China, China

Peter Buchner, Rothamsted Research, UK

*Correspondence:

Karine Gallardo, Institut National de la Recherche Agronomique, UMR1347 Agroécologie, 17 rue de Sully, BP 86510, Dijon, France

e-mail: karine.gallardo@dijon.inra.fr

Drought and salinity are two frequently combined abiotic stresses that affect plant growth, development, and crop productivity. Sulfate, and molecules derived from this anion such as glutathione, play important roles in the intrinsic responses of plants to such abiotic stresses. Therefore, understanding how plants facing environmental constraints re-equilibrate the flux of sulfate between and within different tissues might uncover perspectives for improving tolerance against abiotic stresses. In this review, we took advantage of genomics and post-genomics resources available in Arabidopsis thaliana and in the model legume species Medicago truncatula to highlight and compare the regulation of sulfate transporter genes under drought and salt stress. We also discuss their possible function in the plant's response and adaptation to abiotic stresses and present prospects about the potential benefits of mycorrhizal associations, which by facilitating sulfate uptake may assist plants to cope with abiotic stresses. Several transporters are highlighted in this review that appear promising targets for improving sulfate transport capacities of crops under fluctuating environmental conditions.

\section{Keywords: sulfate, transporters, abiotic stresses, M. truncatula, Arabidopsis}

\section{INTRODUCTION}

Drought, the incidence of which is expected to increase with climatic changes, is one of the major abiotic constraints on agricultural productivity. Because drought is often associated with salinity, one challenge for sustainable agriculture is to breed crops for enhanced tolerance to both stresses. This requires an understanding of the adaptive mechanisms allowing plants to survive in low-water and high-salt environments. Sulfur is a key component in helping plants to cope with such abiotic stresses (for review, see Chan et al., 2013). For example, sulfur is used for the synthesis of glutathione, which acts in the maintenance of the cellular redox balance and mitigates damage caused by reactive oxygen species. Most of the sulfur taken up by plants is in the form of sulfate, and several studies point to a role of this anion in the plant response to drought and salinity in relation to the phytohormone abscisic acid (ABA), a major regulator of leaf stomatal conductance (Wilkinson and Davies, 2002). It was proposed that sulfate acts as a primary signal to enhance the anti-transpirant effect of ABA reaching the stomata in leaves (Ernst et al., 2010). More recently, Cao et al. (2014) provided evidence for a significant co-regulation of sulfur and ABA metabolisms in Arabidopsis that may help to combat environmental stresses. Such metabolic adjustments undoubtedly rely on the plant's ability to absorb and distribute sulfate to the different organs in amounts sufficient to fulfill requirements.

Major advances have been made toward identifying and characterizing the transporters involved in the uptake, distribution, or efflux of sulfate from the vacuoles, especially in Arabidopsis (Buchner et al., 2004 and references therein). The investigation of the contribution of sulfate transporters (SULTR) to abiotic stress tolerance has begun more recently. Cao et al. (2014) proposed a role for SULTR3;1 in helping plants to cope with environmental stresses by providing sulfate for the synthesis of cysteine that serves as a sulfur donor during ABA biosynthesis. With the advances made over the last decade in the integration of "omics" data, gene expression atlases are now available for several species, giving access to the regulation of any gene of interest in different conditions. In this review, we took advantage of these resources to highlight the regulation of SULTR genes in response to drought and salinity. We focus on Arabidopsis and M. truncatula, the latter being a wild legume species originating from the Mediterranean basin that makes use of symbiotic associations to obtain nutrients and that has evolved to develop a tolerance to extreme environmental conditions including drought and salinity (Friesen et al., 2010). After a search of the SULTR sequences in M. truncatula and of their closest homologs in Arabidopsis, we discuss and compare their regulation and possible contribution to protection against unfavorable environmental conditions. We also highlight the potential benefit of using arbuscular mycorrhizal (AM) fungi to improve sulfate uptake.

\section{COMPARATIVE ANALYSIS OF SULTR GENE FAMILIES BETWEEN Arabidopsis AND M. truncatula}

Medicago truncatula is an annual forage species adopted in 2001 as a model for legumes because of its small genome, compared to crop legumes such as pea, and its ability to perform symbiotic interactions with nitrogen-fixing rhizobia and AM fungi, like most legume species (Frugoli and Harris, 2001). The close relationship of the M. truncatula genome with that of pea (Pisum sativum L.) facilitates the transfer of information to the crop, and molecular 


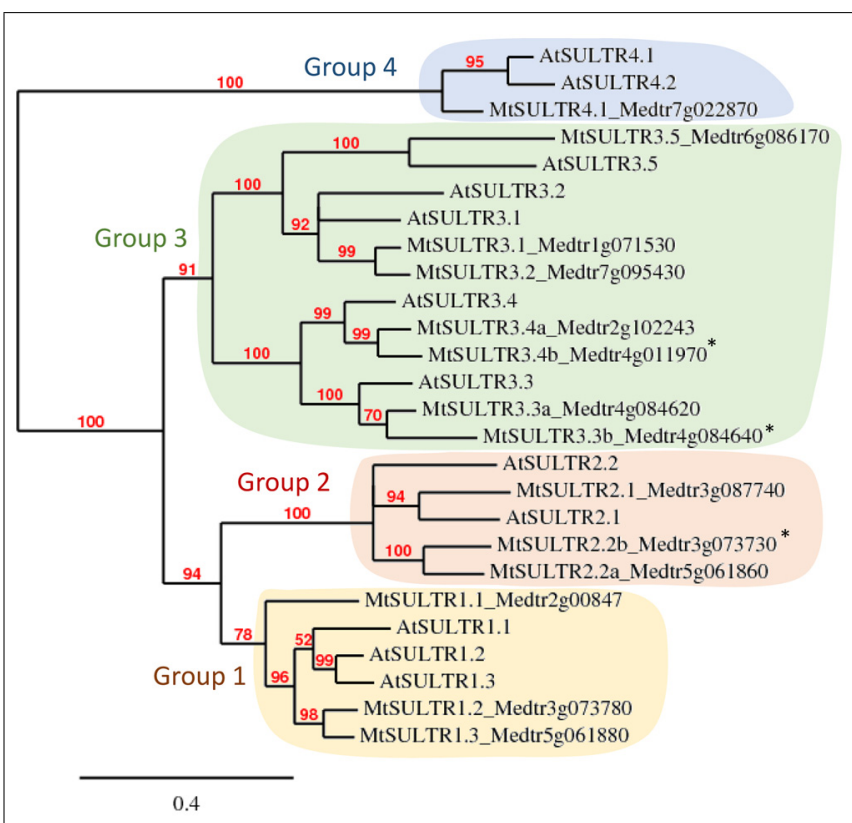

FIGURE 1 | Phylogenetic tree of Medicago truncatula and Arabidopsis sulfate transporters. The Maximum likelihood phylogenetic tree was generated using all SULTR amino acid sequences available in the Arabidopsis and $M$. truncatula (Mt4.0v1) genomic resources. ${ }^{*}$, sequences for which there was no corresponding probe in the Medicago Gene Expression Atlas.

markers have been developed for translational genomics between the two species (Bordat et al., 2011). M. truncatula is native to the arid and semi-arid environments of the Mediterranean. It is thus adapted to this climate, making it a good model to identify adaptation processes to low-water or high-salt stresses. Genomic resources were developed for this species that we used here to retrieve SULTR genes (MtSULTR). Fourteen genes homologous to the Arabidopsis SULTR genes (AtSULTR) were identified in the last Medicago genome version 4.0v1 ${ }^{1}$. Phylogenetic analysis using SULTR full length amino-acid sequences allowed us to re-annotate the MtSULTRs and to refine their phylogenetic relationship with AtSULTRs (Figure 1). The corresponding neighbor-joining tree divided into four clusters matching the four groups described in Arabidopsis (Buchner et al., 2004), as previously observed by Casieri et al. (2013). Three MtSULTRs clustered with the three Arabidopsis transporters of high-affinity belonging to group 1, involved in sulfate uptake (SULTR1;1 and 1;2, Yoshimoto et al., 2007; Barberon et al., 2008) or in its distribution to sink organs (SULTR1;3, Yoshimoto et al., 2003). Three others MtSULTRs clustered with the two Arabidopsis members of group 2 that deliver sulfate to aerial parts and developing tissues (Takahashi et al., 2000; Awazuhara et al., 2005). Group 3 is the largest group, with seven members in M. truncatula compared to five in Arabidopsis. They play multiple roles, such as facilitating sulfate transport to aerial parts or controlling cysteine level in seeds and seedlings in tight interaction with ABA metabolism (Kataoka et al., 2004a; Zuber et al., 2010; Cao et al., 2014). One member of this group,

\footnotetext{
${ }^{1}$ http://www.jcvi.org/medicago/
}

SULTR3;1, is responsible for sulfate transport into chloroplasts (Cao et al., 2013). Within group 4, unlike Arabidopsis which contains two SULTR4 genes, there was only one M. truncatula gene. It encodes a protein with high homology to AtSULTR4;1 which plays a major role in the efflux of sulfate from the vacuole lumen to the cytosol (Kataoka et al., 2004b). This suggests a unique function for MtSULTR4;1 in remobilizing the stored sulfate. This may apply to other species as there is only one transporter of group 4 with high homology to AtSULTR4;1 in pea (RNAseq data, Burstin J, personal communication) and rice (Kumar et al., 2011).

The recent transcriptome analysis of $M$. truncatula subjected to progressive drought (Zhang et al., 2014a) allowed us to investigate the transcriptional regulation of the MtSULTR gene family in response to this abiotic stress and in comparison with a salt stress response (Li et al., 2009). Data were downloaded from the Gene Expression Atlas (MtGEA) ${ }^{2}$, and expression fold-change between treated and non-treated samples was calculated (cutoff of 2.0, Table 1). Expression of three of the $14 M t S U L T R$ genes (MtSULTR2;2b, MtSULTR3;3b, and MtSULTR3;4b, Figure 1) could not be investigated as there was no corresponding probe set in the Affymetrix chip used to build the MtGEA. To compare SULTR gene regulation between M. truncatula and Arabidopsis, we used transcriptomic data available in Arabidopsis for drought and salt stress experiments (Kilian et al., 2007; Huang et al., 2008; Perera et al., 2008; Nishiyama et al., 2012; Geng et al., 2013; Pandey et al., 2013; Wang et al., 2013; Ha et al., 2014). The studies showing the most substantial regulation of SULTR genes are included in Table 1. Results are discussed in the light of functional data available, mainly in Arabidopsis.

\section{SULTR OF GROUP 3 ARE STRONGLY REGULATED BY ABIOTIC STRESSES IN ROOTS}

Of particular interest is the up-regulation of the SULTR3;1 gene in roots of both species subjected to drought and salt stress. Interestingly, the expression of AtSULTR3;1 is enhanced by ABA and required for cysteine synthesis (Cao et al., 2014). Cysteine, whose precursor is sulfate, plays a key role in ABA synthesis as it serves as sulfur donor for the sulfuration of molybdenum, a co-factor needed in its sulfurylated form for the last reaction in the pathway (Xiong et al., 2001). The cysteine formed may also serve for the synthesis of the stress-defense compound glutathione. Cao et al. (2014) proposed that sulfur metabolism and ABA biosynthesis interplay to ensure sufficient cysteine for ABA production under abiotic stresses. From these data and the reported plastid-localization of AtSULTR3;1 (Cao et al., 2013), it is tempting to speculate on a role for this transporter in directing the flux of sulfate toward cysteine biosynthesis in the root plastids that may further be used for ABA production in response to both abiotic stresses. In M. truncatula, SULTR3;1 has not been functionally characterized. However, the gene is up-regulated in response to both abiotic stresses (Table 1) and co-localizes with quantitative trait loci (QTL) regions for salt tolerance (Friesen et al., 2010; Arraouadi et al., 2012), as also observed for AtSULTR3;1 (El-Soda et al., 2014; Zhang et al., 2014c). This

\footnotetext{
${ }^{2}$ http://mtgea.noble.org/v3/
} 
Table 1 | Regulation of SULTR gene expression in Medicago truncatula and Arabidopsis subjected to drought and salt stress.

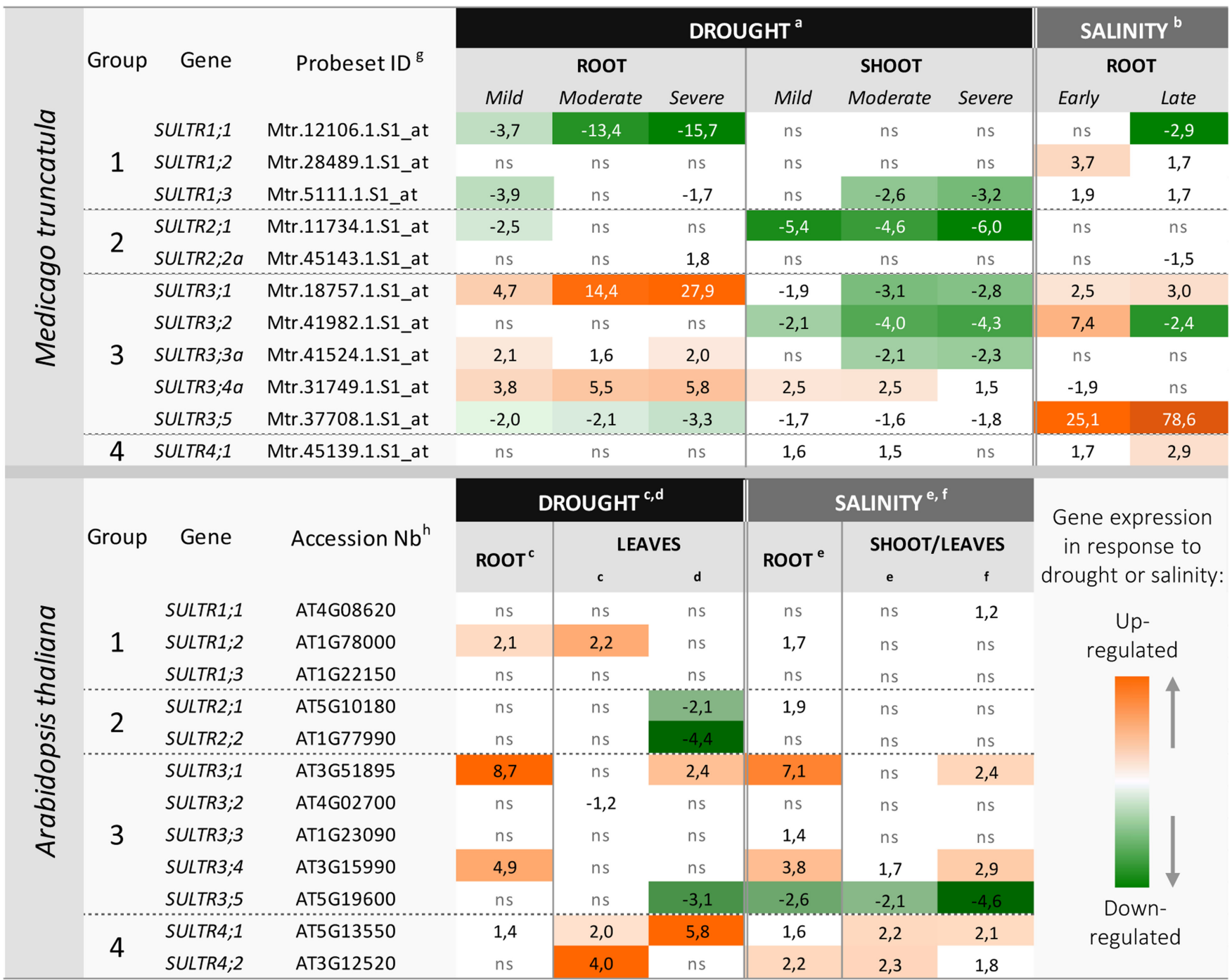

SULTR gene regulation from: (a) Zhang et al. (2014a): mild, moderate or severe water stress (corresponding to 7, 10, or 14 days of water withdrawal, respectively) applied on 24 day-old M. truncatula plants. (b) Li etal. (2009): young seedlings (2 days) treated with $180 \mathrm{mM}$ of NaCl for $6 \mathrm{~h}$ (early response) or 2 days (late reponse); (c) Ha etal. (2014): aerial portions of 24 day-old plants detached and exposed to dehydration on paper towels for 4 h; (d) Pandey et al. (2013): 3 week-old plantlets grown for 9 days on soil with a moisture level below 30\%; (e) Kilian etal. (2007): $150 \mathrm{mM} \mathrm{NaCl}$ applied to Arabidopsis seedlings in vitro; (f) Wang et al. (2013): 10 day-old seedlings grown for 4 days on a medium supplemented with $100 \mathrm{mM} \mathrm{NaCl}$. For each MtSULTR gene, data for the correponding probeset ID (g) were downloaded from the Medicago Gene Expression Atlas at http://mtgea.noble.org/v3/experiments. (h) Genbank accession number of the Arabidopis SULTR genes. The values refer to gene expression fold change between treated and non-treated samples. Changes in gene expression of at least twofold are highlighted using a color scale; ns, non-significant change in gene expression in response to drought or salt stress.

makes MtSULTR3;1 a potential target for modulating the abiotic stress response in legumes. In addition, MtSULTR3;1 expression is higher at late stages of water stress, i.e., severe water stress in Table 1, known to be associated with ABA biosynthesis in roots (Goodger and Schachtman, 2010), suggesting that MtSULTR3;1 could be closely linked in its action with ABA production, as is the case in Arabidopsis (Cao etal., 2014). Another gene of group 3 (AtSULTR3;4, MtSULTR3;4a) is co-expressed in roots with SULTR3;1 in response to drought in the two species and in response to salt stress in Arabidopsis (Table 1). The reduced ABA content in seedlings for the two mutants Atsultr3;1 and Atsultr3;4 suggests a role for both genes in relation to $\mathrm{ABA}$ production.
The subcellular localization of SULTR3;4 is unknown. Investigating spatial and subcellular localizations in roots for both transporters might help to decipher whether they can have a coordinated function or a functional redundancy in this tissue. It should be noted that in contrast to Arabidopsis, MtSULTR3;1 and MtSULTR3; $4 a$ are differentially regulated in response to salt stress (only MtSULTR3; 1 is up-regulated) and that a second MtSULTR3;4 gene (MtSULTR3;4b, Figure 1) exists whose response to salt stress is currently unknown.

In M. truncatula, the expression of another group 3 SULTR (MtSULTR3;5) is strongly up-regulated in roots subjected to salt stress (up to 78-fold; Table 1). Its closest Arabidopsis homolog, 
AtSULTR3;5, shows opposite trends of expression in roots with a consistent down-regulation in response to salinity. This suggests distinct roles or transcriptional regulation of SULTR3;5 between the two species. In the legume species Lotus japonicus, the SULTR3;5 homolog SST1 (Symbiotic Sulfate Transporter 1) is necessary for nodule formation and essential for the symbiotic supply of sulfur to the bacteria (Krusell et al., 2005). In this connection, Varin et al. (2010) identified sulfur supply as necessary for proper accumulation of nitrogenase and leghaemoglobin, two proteins rich in sulfur amino acids and needed for nitrogen fixation. This highlights the importance of maintaining efficient sulfate transport systems in nodules to exploit the nitrogen-fixing capacity of legume plants in agroecological systems. MtSULTR3;5 is strongly expressed in nodules (Roux et al., 2014) and studies are ongoing to understand the function of MtSULTR3;5 in nodules and to deciphering its contribution to the salt stress response.

\section{RE-EQUILIBRATION OF SULFATE FLUX IN AERIAL PARTS IN RESPONSE TO ABIOTIC STRESSES}

In contrast to the functional SST1 (Krusell etal., 2005), AtSULTR3;5 is a non-functional transporter by itself (Kataoka et al., 2004a). This transporter forms a complex with AtSULTR2;1, thus enhancing its sulfate import activity into cells of root vascular tissues for loading into the xylem and transfer to aerial parts, especially when sulfur availability is limited (Takahashi et al., 2000; Kataoka et al., 2004a). The flux of sulfur from roots to shoots is in part controlled by microRNA(Mir)395, which limits expression of SULTR2;1 to xylem parenchyma, thus enhancing sulfate translocation to aerial parts (Kawashima et al., 2011). Interestingly, Mir395 is up-regulated in response to drought stress in rice (Zhou et al., 2010) and under high salinity conditions in maize (Zea mays L.; Ding et al., 2009), suggesting it participates in abiotic stress responses, presumably by maintaining the flux of sulfur toward aerial parts. In roots, the expression of AtSULTR2;1 is not affected by salinity and drought, whereas that of AtSULTR3;5 decreased significantly in response to salt stress (Table 1). Owing to the co-activator function of AtSULTR3;5, this may slow the allocation of sulfate to aerial parts. It is therefore possible that Arabidopsis adjusts the level of sulfate in roots under salt stress by modulating AtSULTR3;5 expression. This could be part of the adaptive mechanisms used by Arabidopsis to load sulfate into xylem vessels while ensuring that sufficient sulfate remains in roots when uptake is limited due to high salt concentrations in soils. In M. truncatula, the SULTR2;1 gene is not significantly regulated in roots in response to salt stress, but down-regulated in this tissue at early stages of water stress. The function of this transporter has not been reported yet, but if we assume a similar role to its Arabidopsis homolog, the down-regulation observed is likely to reflect a need to maintain sulfate in roots at these stages.

A continued loading of sulfate into xylem vessels is of paramount importance for maintaining the synthesis of sulfur molecules in aerial parts. Moreover, sulfate from the xylem acts as a chemical signal for ABA-dependent stomatal closure in leaves during early stages of water stress when ABA biosynthesis is restricted to leaves (Ernst etal., 2010). Several SULTR genes in Table 1 that are regulated in shoots or leaves are good candidates for re-equilibrating the flux of sulfate in aerial parts in response to abiotic stresses. First, SULTR2;1 is significantly down-regulated in leaves of Arabidopsis and M. truncatula subjected to drought. AtSULTR2; 1 has been shown to be not only expressed in the xylem parenchyma cells but also in the phloem cells of mature leaves, where it participates in the translocation of sulfate to young leaves (Takahashi et al., 2000). Hence, the down-regulation of SULTR2;1 suggests a decreased flux of sulfate to young leaves, presumably to save sulfate for protection mechanisms, such as those involving ABA. Second, in M. truncatula subjected to drought, one SULTR3 gene, MtSULTR3;4, is significantly up-regulated in aerial parts and more strongly at early stages of water stress (mild and moderate in Table 1). It would be of particular interest to investigate whether this transporter could play a role in leaves in controlling their early response to water stress in strong connection with ABA biosynthesis. In Arabidopsis, AtSULTR3;1 and 3;4 are both significantly up-regulated in leaves subjected to salt stress, reinforcing the hypothesis raised in the previous section that both transporters could act in concert to mitigate the effect of salt stress.

Interestingly, the expression of both vacuolar AtSULTR4 genes is significantly enhanced in leaves by drought and salinity. Moreover, AtSULTR4;1 and AtSULTR4;2 fall in QTL regions for tolerance to both stresses (Juenger et al., 2005; McKay et al., 2008). They are thus good candidates for multiple stress tolerance. The only SULTR4 gene in M. truncatula is also up-regulated in shoots in response to drought with a statistically significant but lower fold-change compared to Arabidopsis. Because in Arabidopsis, the SULTR4 transporters were shown to enable the mobilization of the sulfate stored in the vacuoles, they may play a critical role in ensuring sulfur metabolism in plant cells when sulfate uptake is limited due to environmental constraints. Furthermore, efflux of sulfate from the vacuole may contribute to osmotic adjustments that play a fundamental role in water and salt stress responses. The role of SULTR4 (Kataoka et al., 2004b) has been investigated in roots but their involvement in shoots merits further investigations in relation to abiotic stress tolerance.

\section{REGULATION OF GENES INVOLVED IN SULFATE UPTAKE UNDER ABIOTIC STRESS CONDITIONS}

The capacity of roots to take up nutrients generally declines in salt- and water-stressed plants, which may explain the changes in expression of SULTR genes belonging to groups 2, 3, and 4 under these conditions to rebalance sulfate flux between affected tissues. By examining the regulation of the two SULTR1 genes known to control sulfate uptake in Arabidopsis, we observed a contrasted pattern for both genes (Table 1). MtSULTR1;1 appeared down-regulated in roots subjected to both abiotic stresses, whereas MtSULTR1;2 and AtSULTR1;2 were up-regulated in response to salinity and drought, respectively. Barberon et al. (2008) demonstrated that SULTR1;1 and SULTR1;2 display unequal functional redundancy in Arabidopsis and left open the possibility for the SULTR1;1 gene to display an additional function besides its role in sulfate membrane transport. Recent findings also proposed a supplementary role for AtSULTR1;2 in the regulatory or sensing/signaling pathways related to sulfur metabolism (Zhang 
et al., 2014b). Further studies are needed to better understand their additional function(s) and contribution to abiotic stress responses.

\section{AM FUNGI, A PROMISING PERSPECTIVE FOR IMPROVING SULFATE UPTAKE IN FLUCTUATING ENVIRONMENTS?}

The emerging role of sulfate in plant adaptation to abiotic stresses reinforces the need to sustain proper sulfate uptake and use in cultures that face environmental stresses. One specific feature of legumes, compared to Arabidopsis, is their ability to perform symbiotic interactions with AM fungi. This mutualistic association is known to increase plant tolerance to drought (Augé, 2001), an abiotic stress limiting the absorption of ions, including sulfate, by roots. Recent studies in M. truncatula revealed that AM fungi improve sulfur nutrition in low-sulfate environments (Casieri et al., 2012; Sieh et al., 2013), probably through their capacity to take up and translocate sulfate to the root (Gray and Gerdemann, 1973; Rhodes and Gerdemann, 1978a,b; Allen and Shachar-Hill, 2009). To date, there is no information available on the regulation of plant sulfate uptake or plant sulfate transporter genes in the presence of AM fungi under drought conditions. However, because drought is associated with reduced sulfate availability, the SULTR genes up-regulated at low sulfate concentrations in roots colonized with AM fungi (Casieri et al., 2012; Sieh etal., 2013) might help the plant partner to survive in such environments. This is the case for MtSULTR1;1 and MtSULTR1;2, both up-regulated in roots of AM symbiotic plants, especially at low sulfate concentrations (Casieri et al., 2012). Recently, Giovannetti et al. (2014) demonstrated the induction of the LjSULTR1;2 gene during the Lotus japonicus/Rhizophagus irregularis mutualistic interaction, and the specific expression of this transporter in arbuscule-containing cells, strongly suggesting AM-specific sulfate transport. Investigating the regulation of such genes during AM symbiosis in response to abiotic stresses might help to decipher the roles played by these transporters in fluctuating environments.

\section{CONCLUSION}

Several SULTR genes regulated by drought and/or salinity were highlighted in this review that may contribute to adjust sulfur distribution in plants subjected to abiotic stresses. We discussed their possible roles using information available in Arabidopsis, for which considerable advances have been made in the last two decades toward understanding SULTR functions, more recently in response to salinity (Cao et al., 2014). SULTR genes similarly regulated in Arabidopsis and M. truncatula are promising targets for improving sulfate transport capacities under fluctuating environmental conditions. Among these are group 3 SULTR, also in the list of abiotic stress-responsive genes shared between Arabidopsis and M. truncatula of Hyung et al. (2014). Group 1 SULTR are other potential targets for enhancing sulfate uptake in fluctuating environmental conditions. Members of this group were found to be up-regulated by drought stress and by AM fungi associations that increased significantly the root uptake of sulfate in low-sulfate environments, as it is the case in drought conditions. Broad collections of ecotypes and TILLING mutants are available in M. truncatula and in the pea crop
(Dalmais et al., 2008; Le Signor et al., 2009; Deulvot et al., 2010) that can be used to study and confirm SULTR genes as relevant candidates for discovering favorable alleles for abiotic stress tolerance.

\section{ACKNOWLEDGMENTS}

Present work of the authors on sulfate transport is done in the frame of the European Community's Seventh Framework Programme (FP7/2007-2013) under the grant agreement number FP7-613551, LEGATO project. Pierre-Emmanuel Courty gratefully acknowledges his current support by the Swiss National Science Foundation through an AMBIZIONE fellowship (grant No. PZ00P3_136651).

\section{REFERENCES}

Allen, J. W., and Shachar-Hill, Y. (2009). Sulfur transfer through an arbuscular mycorrhiza. Plant Physiol. 149, 549-560. doi: 10.1104/pp.108.129866

Arraouadi, S., Badri, M., Abdelly, C., Huguet, T., and Aouani, M. E. (2012). QTL mapping of physiological traits associated with salt tolerance in Medicago truncatula Recombinant Inbred Lines. Genomics 99, 118-125. doi: 10.1016/j.ygeno.2011.11.005

Augé, R. M. (2001). Water relations, drought and vesicular-arbuscular mycorrhizal symbiosis. Mycorrhiza 11, 3-42. doi: 10.1007/s005720100097

Awazuhara, M., Fujiwara, T., Hayashi, H., Watanabe-Takahashi, A., Takahashi, H., and Saito, K. (2005). The function of SULTR2;1 sulfate transporter during seed development in Arabidopsis thaliana. Plant Physiol. 125, 95-105. doi: 10.1111/j.1399-3054.2005.00543.x

Barberon, M., Berthomieu, P., Clairotte, M., Shibagaki, N., Davidian, J.-C., and Gosti, F. (2008). Unequal functional redundancy between the two Arabidopsis thaliana high-affinity sulphate transporters SULTR1;1 and SULTR1;2. New Phytol. 180, 608-619. doi: 10.1111/j.1469-8137.2008. 02604.x

Bordat, A., Savois, V., Nicolas, M., Salse, J., Chauveau, A., Bourgeois, M., et al. (2011). Translational genomics in legumes allowed placing in silico 5460 unigenes on the pea functional map and identified candidate genes in Pisum sativum L. G3 (Bethesda) 1, 93-103. doi: 10.1534/g3.111.000349

Buchner, P., Takahashi, H., and Hawkesford, M. J. (2004). Plant sulphate transporters: co-ordination of uptake, intracellular and long-distance transport. J. Exp. Bot. 55, 1765-1773. doi: 10.1093/jxb/erh206

Cao, M. J., Wang, Z., Wirtz, M., Hell, R., Oliver, D. J., and Xiang, C. B. (2013). SULTR3;1 is a chloroplast-localized sulfate transporter in Arabidopsis thaliana. Plant J. 73, 607-616. doi: 10.1111/tpj.12059

Cao, M. J., Wang, Z., Zhao, Q., Mao, J. L., Speiser, A., Wirtz, M., et al. (2014). Sulfate availability affects ABA levels and germination response to ABA and salt stress in Arabidopsis thaliana. Plant J. 77, 604-615. doi: 10.1111/tpj. 12407

Casieri, L., Ait Lahmidi, N., Doidy, J., Veneault-Fourrey, C., Migeon, A., Bonneau, L., et al. (2013). Biotrophic transportome in mutualistic plant-fungal interactions. Mycorrhiza 23, 597-625. doi: 10.1007/s00572-013-0496-9

Casieri, L., Gallardo, K., and Wipf, D. (2012). Transcriptional response of Medicago truncatula sulphate transporters to arbuscular mycorrhizal symbiosis with and without sulphur stress. Planta 235, 1431-1447. doi: 10.1007/s00425-0121645-7

Chan, K. X., Wirtz, M., Phua, S. Y., Estavillo, G. M., and Pogson, B. J. (2013). Balancing metabolites in drought: the sulfur assimilation conundrum. Trends Plant Sci. 18, 18-29. doi: 10.1016/j.tplants.2012.07.005

Dalmais, M., Schmidt, J., Le Signor, C., Moussy, F., Burstin, J., Savois, V., et al. (2008). UTILLdb, a Pisum sativum in silico forward and reverse genetics tool. Genome Biol. 9, R43. doi: 10.1186/gb-2008-9-2-r43

Deulvot, C., Charrel, H., Marty, A., Jacquin, F., Donnadieu, C., Lejeune-Hénaut, I., et al. (2010). Highly-multiplexed SNP genotyping for genetic mapping and germplasm diversity studies in pea. BMC Genomics 11:468. doi: 10.1186/14712164-11-468

Ding, D., Zhang, L., Wang, H., Liu, Z., Zhang, Z., and Zheng, Y. (2009). Differential expression of miRNAs in response to salt stress in maize roots. Ann. Bot. 103, 29-38. doi: 10.1093/aob/mcn205 
El-Soda, M., Kruijer, W., Malosetti, M., Koornneef, M., and Aarts, M. G. (2014). Quantitative trait loci and candidate genes underlying genotype by environment interaction in the response of Arabidopsis thaliana to drought. Plant Cell Environ. doi: 10.1111/pce.12418 [Epub ahead of print].

Ernst, L., Goodger, J. Q., Alvarez, S., Marsh, E. L., Berla, B., Lockhart, E., et al. (2010). Sulphate as a xylem-borne chemical signal precedes the expression of ABA biosynthetic genes in maize roots. J. Exp. Bot. 61, 3395-3405. doi: $10.1093 /$ jxb/erq160

Friesen, M. L., Cordeiro, M. A., Penmetsa, R. V., Badri, M., Huguet, T., Aouani, M. E., et al. (2010). Population genomic analysis of Tunisian Medicago truncatula reveals candidates for local adaptation. Plant J. 63, 623-635. doi: 10.1111/j.1365313X.2010.04267.x

Frugoli, J., and Harris, J. (2001). Medicago truncatula on the move! Plant Cell. 13, 458-463. doi: 10.1105/tpc.13.3.458

Geng, Y., Wu, R., Wee, C. W., Xie, F., Wei, X., Chan, P. M., et al. (2013). A spatiotemporal understanding of growth regulation during the salt stress response in Arabidopsis. Plant Cell 25, 2132-2154. doi: 10.1105/tpc.113.112896

Giovannetti, M., Tolosano, M., Volpe, V., Kopriva, S., and Bonfante, P. (2014). Identification and functional characterization of a sulfate transporter induced by both sulfur starvation and mycorrhiza formation in Lotus japonicus. New Phytol. 204, 609-619. doi: 10.1111/nph.12949

Goodger, J. Q., and Schachtman, D. P. (2010). Re-examining the role of ABA as the primary long-distance signal produced by water-stressed roots. Plant Signal. Behav. 5, 1298-1301. doi: 10.4161/psb.5.10.13101

Gray, L. E., and Gerdemann, J. W. (1973). Uptake of sulphur-35 by vesiculararbuscular mycorrhizae. Plant Soil 39, 687-689. doi: 10.1007/BF00264184

Ha, C. V., Leyva-González, M. A., Osakabe, Y., Tran, U. T., Nishiyama, R., Watanabe, Y., et al. (2014). Positive regulatory role of strigolactone in plant responses to drought and salt stress. Proc. Natl. Acad. Sci. U.S.A. 111, 851-856. doi: 10.1073/pnas.1322135111

Huang, D., Wu, W., Abrams, S. R., and Cutler, A. J. (2008). The relationship of drought-related gene expression in Arabidopsis thaliana to hormona and environmental factors. J. Exp. Bot. 59, 2991-3007. doi: 10.1093/jxb/ ern 155

Hyung, D., Lee, C., Kim, J. H., Yoo, D., Seo, Y. S., Jeong, S. C., et al. (2014). Cross-family translational genomics of abiotic stress-responsive genes between Arabidopsis and Medicago truncatula. PLoS ONE 9:e91721. doi: 10.1371/journal.pone.0091721

Juenger, T. E., McKay, J. K., Hausmann, N., Keurentjes, J. J. B., Sen, S., Stowe, K. A., et al. (2005). Identification and characterization of QTL underlying wholeplant physiology in Arabidopsis thaliana: Delta C-13, stomatal conductance and transpiration efficiency. Plant Cell Environ. 28, 697-708. doi: 10.1111/j.13653040.2004.01313.x

Kataoka, T., Hayashi, N., Yamaya, T., and Takahashi, H. (2004a). Root-to-shoot transport of sulfate in Arabidopsis. Evidence for the role of SULTR3;5 as a component of low-affinity sulfate transport system in the root vasculature. Plant Physiol. 136, 4198-4204. doi: 10.1104/pp.104.045625

Kataoka, T., Watanabe-Takahashi, A., Hayashi, N., Ohnishi, M., Mimura, T., Buchner, P., et al. (2004b). Vacuolar sulfate transporters are essential determinants controlling internal distribution of sulfate in Arabidopsis. Plant Cell 16, 2693-2704. doi: 10.1105/tpc.104.023960

Kawashima, C. G., Matthewman, C. A., Huang, S., Lee, B. R., Yoshimoto, N., Koprivova, A., et al. (2011). Interplay of SLIM1 and miR395 in the regulation of sulfate assimilation in Arabidopsis. Plant J. 66, 863-876. doi: 10.1111/j.1365313X.2011.04547.x

Kilian, J., Whitehead, D., Horak, J., Wanke, D., Weinl, S., Batistic, O., et al. (2007). The AtGenExpress global stress expression data set: protocols, evaluation and model data analysis of UV-B light, drought and cold stress responses. Plant J. 50, 347-363. doi: 10.1111/j.1365-313X.2007.03052.x

Krusell, L., Krause, K., Ott, T., Desbrosses, G., Krämer, U., Sato, S., et al. (2005). The sulfate transporter SST1 is crucial for symbiotic nitrogen fixation in Lotus japonicus root nodules. Plant Cell 17, 1625-1636. doi: 10.1105/tpc.104. 030106

Kumar, S., Asif, M. H., Chakrabarty, D., Tripathi, R. D., and Trivedi, P. K. (2011). Differential expression and alternative splicing of rice sulphate transporter family members regulate sulphur status during plant growth, development and stress conditions. Funct Integr Genomics 11, 259-273. doi: 10.1007/s10142-0100207-y
Le Signor, C., Savois, V., Aubert, G., Verdier, J., Nicolas, M., Pagny, G., et al. (2009). Optimizing TILLING populations for reverse genetics in Medicago truncatula. Plant Biotechnol. J. 7, 430-441. doi: 10.1111/j.1467-7652.2009.00410.x

Li, D., Su, Z., Dong, J., and Wang, T. (2009). An expression database for roots of the model legume Medicago truncatula under salt stress. BMC Genomics 10:517. doi: 10.1186/1471-2164-10-517

McKay, J. K., Richards, J. H., Nemali, K. S., Sen, S., Mitchell-Olds, T., Boles, S., et al. (2008). Genetics of drought adaptation in Arabidopsis thaliana II. QTL analysis of a new mapping population, Kas-1 × Tsu-1. Evolution 62, 3014-3026. doi: 10.1111/j.1558-5646.2008.00474.X

Nishiyama, R., Le, D. T., Watanabe, Y., Matsui, A., Tanaka, M., Seki, M., et al. (2012). Transcriptome analyses of a salt-tolerant cytokinin-deficient mutant reveal differential regulation of salt stress response by cytokinin deficiency. PLoS ONE 7:e32124. doi: 10.1371/journal.pone.0032124

Pandey, N., Ranjan, A., Pant, P., Tripathi, R. K., Ateek, F., Pandey, H. P., et al. (2013). CAMTA 1 regulates drought responses in Arabidopsis thaliana. BMC Genomics 14:216. doi: 10.1186/1471-2164-14-216

Perera, I. Y., Hung, C. Y., Moore, C. D., Stevenson-Paulik, J., and Boss, W. F. (2008). Transgenic Arabidopsis plants expressing the type 1 inositol 5-phosphatase exhibit increased drought tolerance and altered abscisic acid signaling. Plant Cell 20, 2876-2893. doi: 10.1105/tpc.108.061374

Rhodes, L. H., and Gerdemann, J. W. (1978a). Hyphal translocation and uptake of sulfur by vesicular-arbuscular mycorrhizae of onion. Soil Biol. Biochem. 10, 355-360. doi: 10.1016/0038-0717(78)90057-3

Rhodes, L. H., and Gerdemann, J. W. (1978b). Influence of phosphorus nutrition on sulphur uptake by vesicular arbuscular. Soil Biol. Biochem. 10, 361-364. doi: 10.1016/0038-0717(78)90058-5

Roux, B., Rodde, N., Jardinaud, M. F., Timmers, T., Sauviac, L., Cottret, L., et al. (2014). An integrated analysis of plant and bacterial gene expression in symbiotic root nodules using laser-capture microdissection coupled to RNA sequencing. Plant J. 77, 817-837. doi: 10.1111/tpj.12442

Sieh, D., Watanabe, M., Devers, E. A., Brueckner, F., Hoefgen, R., and Krajinski, F. (2013). The arbuscular mycorrhizal symbiosis influences sulfur starvation responses of Medicago truncatula. New Phytol. 197, 606-616. doi: $10.1111 /$ nph. 12034

Takahashi, H., Watanabe-Takahashi, A., Smith, F. W., Blake-Kalff, M., Hawkesford, M. J., and Saito, K. (2000). The roles of three functional sulphate transporters involved in uptake and translocation of sulphate in Arabidopsis thaliana. Plant J. 23, 171-182. doi: 10.1046/j.1365-313x.2000.00768.x

Varin, S., Cliquet, J. B., Personeni, E., Avice, J.-C., and Lemauviel-Lavenant, S. (2010). How does sulphur availability modify $\mathrm{N}$ acquisition of white clover (Trifolium repens L.)? J. Exp. Bot. 61, 225-234. doi: 10.1093/jxb/erp303

Wang, Y., Yang, L., Zheng, Z., Grumet, R., Loescher, W., Zhu, J. K., et al. (2013). Transcriptomic and physiological variations of three Arabidopsis ecotypes in response to salt stress. PLoS ONE 8:e69036. doi: 10.1371/journal.pone.0069036

Wilkinson, S., and Davies, W. J. (2002). ABA-based chemical signaling: the coordination of responses to stress in plants. Plant Cell Environ. 25, 195-210. doi: 10.1046/j.0016-8025.2001.00824.x

Xiong, L., Ishitani, M., Lee, H., and Zhu, J. K. (2001). The Arabidopsis LOS5/ABA3 locus encodes a molybdenum cofactor sulfurase and modulates cold stressand osmotic stress-responsive gene expression. Plant Cell 13, 2063-2083. doi: 10.1105/tpc.13.9.2063

Yoshimoto, N., Inoue, E., Saito, K., Yamaya, T., and Takahashi, H. (2003). Phloem-localizing sulfate transporter, Sultr 1;3, mediates re-distribution of sulfur from source to sink organs in Arabidopsis. Plant Physiol. 131, 1511-1517. doi: 10.1104/pp.014712

Yoshimoto, N., Inoue, E., Watanabe-Takahashi, A., Saito, K., and Takahashi, H. (2007). Posttranscriptional regulation of high-affinity sulfate transporters in Arabidopsis by sulfur nutrition. Plant Physiol. 145, 378-388. doi: 10.1104/pp.107.105742

Zhang, J. Y., Cruz, D. E., Carvalho, M. H., Torres-Jerez, I., Kang, Y., Allen, S. N., et al. (2014a). Global reprogramming of transcription and metabolism in Medicago truncatula during progressive drought and after rewatering. Plant Cell Environ. In press (free access online). doi: 10.1111/pce.12328 [Epub ahead of print].

Zhang, B., Pasini, R., Dan, H., Joshi, N., Zhao, Y., Leustek, T., et al. (2014b). Aberrant gene expression in the Arabidopsis SULTR1;2 mutants suggests a possible regulatory role for this sulfate transporter in response to sulfur nutrient status. Plant J. 77, 185-197. doi: 10.1111/tpj.12376 
Zhang, X., Lu, G., Long, W., Zou, X., Li, F., and Nishio, T. (2014c). Recent progress in drought and salt tolerance studies in Brassica crops. Breed Sci. 64, 60-73. doi: 10.1270/jsbbs.64.60

Zhou, L., Liu, Y., Liu, Z., Kong, D., Duan, M., and Luo, L. (2010). Genome-wide identification and analysis of drought-responsive microRNAs in Oryza sativa. J. Exp. Bot. 61, 4157-4168. doi: 10.1093/jxb/erq237

Zuber, H., Davidian, J.-C., Aubert, G., Aimé, D., Belghazi, M., Lugan, R., et al. (2010). The seed composition of Arabidopsis mutants for the group 3 sulfate transporters indicates a role in sulfate translocation within developing seeds. Plant Physiol. 154, 913-926. doi: 10.1104/pp.110.162123

Conflict of Interest Statement: The authors declare that the research was conducted in the absence of any commercial or financial relationships that could be construed as a potential conflict of interest.
Received: 27 August 2014; accepted: 08 October 2014; published online: 29 October 2014.

Citation: Gallardo K, Courty P-E, Le Signor C, Wipf D and Vernoud V (2014) Sulfate transporters in the plant's response to drought and salinity: regulation and possible functions. Front. Plant Sci. 5:580. doi: 10.3389/fpls.2014.00580

This article was submitted to Plant Physiology, a section of the journal Frontiers in Plant Science.

Copyright (c) 2014 Gallardo, Courty, Le Signor, Wipf and Vernoud. This is an open-access article distributed under the terms of the Creative Commons Attribution License (CC BY). The use, distribution or reproduction in other forums is permitted, provided the original author(s) or licensor are credited and that the original publication in this journal is cited, in accordance with accepted academic practice. No use, distribution or reproduction is permitted which does not comply with these terms. 